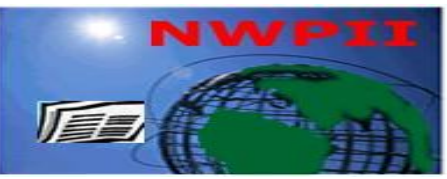

American Journal of Biomedical Sciences

ISSN: 1937-9080

nwpii.com/ajbms

\title{
pH Effects on the Bio-Permeability of Polymers Used in Prophylactics
}

\section{Janice Tubman ${ }^{1}$, Jiamila Maimaiti ${ }^{1}$, Maher El Masri ${ }^{2}$, Susan Fox-Wasylyshyn ${ }^{2}$, Debbie Kane ${ }^{2}$, Trinh T. X. Nguyen ${ }^{1}$, Eleanor Maticka-Tyndale ${ }^{3}$, Lisa A. Porter ${ }^{* 1}$}

\author{
${ }^{1}$ Department of Biological Sciences, University of Windsor, ON. N9B3P4, Canada \\ ${ }^{2}$ Nursing, University of Windsor, ON. N9B3P4, Canada \\ ${ }^{3}$ Sociology and Anthropology, University of Windsor, ON. N9B3P4, Canada \\ * Corresponding author:
}

Lisa A. Porter, PhD

Department of Biological Sciences

University of Windsor

Windsor, Ontario N9B 3P4

Canada

Phone: (519) 253-3000 x4775

Fax: (519) 571-3609

Email:1porter@uwindsor.ca

Received: 9 June 2011; | Revised: 2 September 2011; | Accepted: 18 September 2011

\begin{abstract}
Barrier materials used in medical gloves and condoms to prevent the penetration of infectious agents are of utmost importance for the preservation of public health. Surrogate viruses have proven effective as conservative measures of infectious potential. Previous work has tested the integrity of barrier materials exposed to a host of pressures and stresses, however none have tested the effects of $\mathrm{pH}$ exposure mimicking that prevailing through coitus. We optimized the use of bacteriophage $\Phi$ X174 and PCR detection to conduct a pilot study on the effects of $\mathrm{pH}$ on the viral penetration of latex condoms. Our results suggest that exposure of condoms to acidic $\mathrm{pH}$ ranges of physiological significance increases the frequency of condom failure rate. This proof of principal work supports the need for a larger study to investigate the significance of these effects over a wide range of condom brands.
\end{abstract}

Keywords: Viral penetrability, bacteriophage $\Phi$ X174, natural rubber latex, prophylactics.

\section{Introduction}

Risk of infection from blood borne pathogens and sexually transmitted infections (STIs) stress the need for effective prophylactics. Natural rubber latex (NRL) is the most frequently used barrier material due to its tensile strength and effectiveness against the transmission of a vast number of infectious agents. NRL consists of both high molecular weight proteins which are tightly bound to the rubber particles in the latex, and low molecular weight water soluble proteins which are primarily removed during the manufacturing process of gloves and condoms [1]. The flexibility 
of the cross-linked polymeric material imparts the inherent characteristic of permeability to some substances. Ethanol, alcohol-based disinfectants, organic monomers and several solvents can readily permeate through NRL and have shown differential effects on the barrier function of NRL [2-5]. Indeed, exposure to oil based products, acrylic monomers, chloroform and specific solvents have demonstrated the potential to jeopardize the efficacy of NRL condoms [2,6]. While there are a few independent studies describing the effects of these different variables on the durability of NRL, few include measures of bio-permeability and none have determined the effects of $\mathrm{pH}$ on viral penetrability. Gloves utilized in a laboratory environment may be exposed to a range of $\mathrm{pHs}$ and vaginal $\mathrm{pH}$ ranges from 3.6 - 5.0 [7, 8], hence representing a relatively acidic environment and stressing the need to study this in NRL condoms. Exposure of pre-vulcanized latex films to acidic environments of $\mathrm{pH} 2.0-6.5$ have shown significant effects on total extractable protein content as well as decreasing the crosslink density and tensile strength of the film [9]. However whether exposure following processing also compromises the integrity of NRL is not known.

Prior to use, prophylactics are tested using visual inspection and a "water leak test", approved by the Food and Drug Administration (FDA) and the American Society for Testing [10]. While these detect gross physical defects in the materials, they are not an adequate measure of integrity. Previous studies have determined that bacteriophage Phi-X174 (ФX174) is an excellent surrogate virus to use in barrier testing as it is stable under most test conditions and is compatible with a wide range of barrier materials tested [11, 12]. Bacteriophage resemble the spherical morphology of human viruses and is the appropriate size to be a conservative test virus: ФX174 is $27 \mathrm{~nm}$ in diameter, smaller than most viruses of concern including human immunodeficiency virus (HIV) $(120 \mathrm{~nm})$ and Hepatitis B (47 nm) [13]. Herein we optimize the system described by Lytle et. al. [11] to include a previously described PCR detection step [14] to sensitize and confirm detection of the surrogate virus. We use this system to examine the effect of a range of physiologically significant $\mathrm{pHs}$ on a variety of brands and styles of latex condoms.

\section{Materials and Methods}

\subsection{Preparation of bacteriophage $\Phi \times 174$ and Escherichia coli (E. coli) stocks.}

Stock cultures of bacteriophage $\Phi$ X174 (\#13706-B1) and its bacterial host, E. coli (\#13706), were obtained from American Type Culture Collection (ATCC). E. coli stock were activated on Nutrient Agar (NA; Fisher Scientific; DF0001-17-0), a single colony was grown in Nutrient Broth (NB; Fisher Scientific; DF000317-8) and stored at $-80^{\circ} \mathrm{C}$ in $30 \%$ glycerol.

Bacteriophage stock $(100 \mu \mathrm{l})$ was added to E.coli grown in $50 \mathrm{ml}$ of $\mathrm{NB}$ at $37^{\circ} \mathrm{C}$ with constant shaking $(250 \mathrm{rpm})$ to reach an OD $(600 \mathrm{~nm})$ of 0.3-0.4. Bacteriophage infected E.coli cultures were incubated at $37^{\circ} \mathrm{C}$ with shaking and OD monitored until the density of the culture stopped dropping. Cell debris and unlysed cells were removed by centrifugation at $3000-4000 \mathrm{rpm}$ for $10 \mathrm{~min}$. The supernatant was filtered using a $0.2 \mu$ $\mathrm{m}$ filter and viral titre determined by plaque assay. The bacteriophage stocks, of known titre, were stored at $-80^{\circ} \mathrm{C}$ in NB.

\subsection{Plaque and growth assays for bacteriophage ФX174.}

Propagated bacteriophage $\Phi$ X174 was diluted 10 fold to $10^{-8}$ and $100 \mu \mathrm{l}$ of each dilution was mixed with $100 \mu 1$ of E. coli (OD 0.3). The mixtures were mixed with $4 \mathrm{ml}$ of semi-NA $(0.8 \%$ agar), immediately poured on NA plates and incubated at $37^{\circ} \mathrm{C}$ for $8 \mathrm{~h}$. Plaque forming units (PFU) were calculated by dividing the plate into quadrants, counting the colonies that formed in each quadrant and totaling the amount of colonies.

$\mathrm{PFU} / \mu 1$ was calculated as: total number of colonies / (dilution factor $\mathrm{x}$ volume of diluted virus added to plate). The known concentration of bacteriophage was then collected by scraping the top semi-NA into $2 \mathrm{ml}$ of $\mathrm{NB}$ followed by centrifugation at $3000 \mathrm{rpm}$ at $4^{\circ} \mathrm{C}$ for $15 \mathrm{~min}$. The mixture was sterile filtered and stored at $-80^{\circ} \mathrm{C}$. 
For the growth curve a viral titre of $\sim 10^{8} \mathrm{PFU}$ of bacteriophage $\Phi$ X174 was used to infect $20 \mathrm{ml}$ of E. coli culture with an OD of 0.3 . The culture infected with $\Phi \times 174$ was shaken at $37^{\circ} \mathrm{C}$ at 250 rpm. The culture OD was checked every $20 \mathrm{~min}$ for $3 \mathrm{~h}$.

\subsection{Assay for bio-permeability.}

Condoms to be tested were removed from their original packaging, washed with sterilized PBS (8 g NACl, 0.2 g KCl, 1.44 g Na2 $\mathrm{HPO}_{4}, 0.24$ $\mathrm{g} \mathrm{KH}_{2} \mathrm{PO}_{4}$ in $1 \mathrm{~L} \mathrm{H}_{2} \mathrm{O}$ ) to remove the lubricant and either used as controls or treated in sterile, sealable containers with different $\mathrm{pH}$ solutions. Positive controls were punctured with either a 26 gauge (G) (BD Biosciences; $0.46 \mathrm{~mm}$ diameter hole), $31 \mathrm{G}$ (BD Biosciences; $0.254 \mathrm{~mm}$ diameter hole) or a 42 G (AA Medical Supplies No. A1-42; $0.12 \mathrm{~mm}$ diameter hole) needle. Negative controls were left un-punctured; positives in these samples indicate a basal failure rate. For testing, all condoms used an experimental design previously described by Lytle et. al. [11]. In brief, $100 \mathrm{~mL}$ of water and $10^{8} \mathrm{PFU}$ of bacteriophage $\Phi \mathrm{X} 174$ were placed inside of each condom. Condoms were lowered gently into a flask containing $1 \mathrm{~L}$ of water and secured by draping the uppermost edge of the condom over the lip of the flask and covering it with a tight foil lid. The apparatus was placed on a stir plate and allowed to gently stir for $1 \mathrm{~h}$. Samples were taken from the inside of control condoms as a positive control and then from the outside of all condoms to assay for permeability. $200 \mu \mathrm{l}$ of collected sample was then mixed with 4 $\mathrm{ml}$ of semi-agar containing $200 \mu \mathrm{l}$ of E. coli and poured onto NA plates. The plates were incubated at $37^{\circ} \mathrm{C}$ overnight. Plaques were counted and recorded; the top semi-agar was scraped with $2 \mathrm{ml}$ of NB and centrifuged at $3000 \mathrm{rpm}$ for $10 \mathrm{~min}$ at $4^{\circ} \mathrm{C}$. The supernatant was collected and used to detect DNA for bacteriophage $\phi X 174$ via PCR.

\subsection{PCR conditions.}

Bacteriophage genomic DNA was extracted using Qiaprep spin M13 kit (Qiagen) and quantified using a Biomate spectrophotometer (Thermo Electron Corporation). The PCR mixture (total volume $12.5 \mu \mathrm{l}$ ) consisted of $6.25 \mu \mathrm{l}$ of Taq 2x Master Mix (NEB M0270L), $0.25 \mu$ of each primer solution $(0.2 \mu \mathrm{M}), 2 \mu \mathrm{l}$ of sample and 3.25 $\mu 1$ of nuclease-free water. Primers (5'GCTTGCGTTTATGGTACG-3' and 5'ATACGAAGGCGCAATAACG-3') were previously described [14]. PCR reactions were carried out in a Px2 Thermal Cycle (Thermo Electron Corp.) using the following conditions: 5 min pre-incubation at $94^{\circ} \mathrm{C} ; 25$ cycles of $94^{\circ} \mathrm{C}$ for $45 \mathrm{sec}, 54^{\circ} \mathrm{C}$ for $1 \mathrm{~min}$, and $72^{\circ} \mathrm{C}$ for $1 \mathrm{~min}$; and $10 \mathrm{~min}$ at $72^{\circ} \mathrm{C}$ post-incubation. The PCR products were visualized on a $1 \%$ agarose gel stained with ethidium bromide and imaged through GeneSync Imaging.

\section{Results}

\subsection{Limit of bacteriophage detection}

The growth phase of bacteriophage $\Phi \times 174$ was determined by measuring the OD of E. coli every $20 \mathrm{~min}$ after infection (Fig. 1A). E. coli growth began dropping at $60 \mathrm{~min}$ following infection and reached maximum lysis at $120 \mathrm{~min}$ postinfection. Hence the optimal growth for bacteriophage $\Phi \times 174$ was determined to be the midpoint of the lytic phase 100-120 min. The limit of detection of propagated bacteriophage $\Phi$ X174 DNA by PCR was determined by serially diluting extracted $\Phi$ X174 genomic DNA. The lowest detectable amount by PCR was determined to be 8 pg (Fig.1B). To determine the limit of bacteriophage detection in host cell lysates, a stock suspension of bacteriophage was serially diluted and $1 \mu \mathrm{l}$ used either for PCR amplification or for plaque assay. Our data indicates that 70 $\mathrm{PFU} / \mu \mathrm{L}$ of sample corresponds to the limit of detection for bacteriophage DNA by PCR (Fig.1C).

\subsection{Optimization of test system}

Optimization was first performed to ensure that no aspect of the test system interfered with the detection of bacteriophage $\Phi \times 174$. This is important as previous studies determined that electrostatic and hydrophobic binding of the 
surrogate virus depends on the test material and that the presence of certain surfactants can result in chemical inactivation of the virus [15]. As a positive control condoms were punctured with either a $26 \mathrm{G}$ or a $42 \mathrm{G}$ needle and one condom of each puncture size was placed in a flask containing water, while another was placed in a flask containing NB. It was determined that $\Phi X 174$ could be readily detected using both water and NB for the $26 \mathrm{G}$ puncture (Fig. 2A; bands 2 and 6). However the $42 \mathrm{G}$ needle resulted in only faint detection of bacteriophage using water media but significant detection when using NB media (Fig. 2A; bands 4 and 8). Water sampled from inside and outside of condoms was amplified using PCR before (Fig. 2B; left hand columns) and after (Fig. 2B; right hand columns) a plaque assay. Results demonstrate that there was significantly improved detection of $\Phi$ X174 using an overnight incubation on semi-agar prior to PCR detection.

A

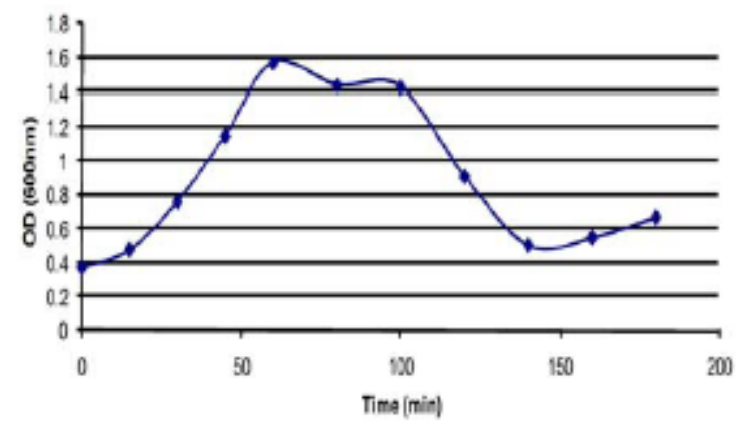

B

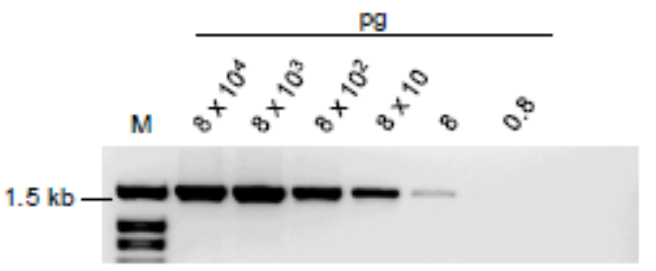

C

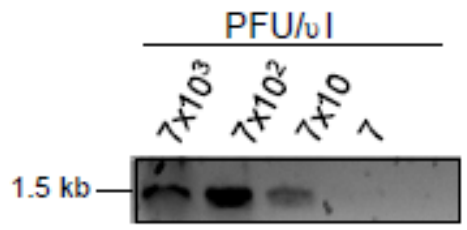

Figure 1. Optimizing the detection of bacteriophage ФX174. (A) E.coli was infected with stock cultures of ФX174 and the OD was measured every $20 \mathrm{~min}$ for $2 \mathrm{~h}$. Data points represent one OD measurement at each time point. (B) PCR detection of a serial dilution of bacteriophage XX174 genomic DNA. Column containing a $1.5 \mathrm{~kb}$ DNA ladder is indicated as $\mathrm{M}$, with $\Phi X 174$ amplifying at the expected $1.5 \mathrm{~kb}$ band. This is one representative gel of over 3. (C) Viral titres corresponding with PCR detection of $\Phi X 174$. Columns indicate the corresponding titre for a serial dilution of bacteriophage $\Phi \mathrm{X} 174$.

A

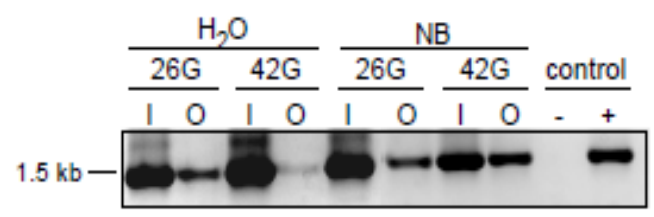

B

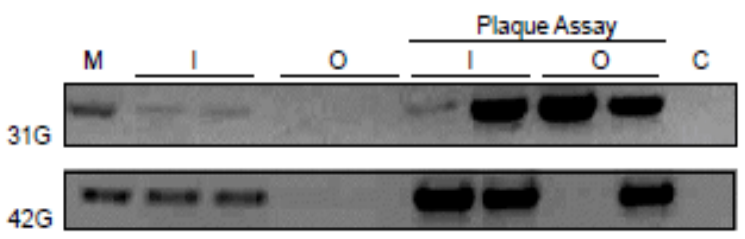

Figure 2. Optimization of controls and test medium. (A) Condoms punctured with either a $26 \mathrm{G}$ or $42 \mathrm{G}$ needle and incubated in either water $(\mathrm{H} 2 \mathrm{O}$; left columns) or nutrient broth (NB; right columns). Samples from inside (I) and outside (O) of the condoms were collected and viral DNA was amplified using PCR. A sample with no DNA was used as the negative control (-) and a sample with $1 \mu \mathrm{g}$ of $\Phi \mathrm{X} 17$ DNA was loaded as the positive control $(+)$. One representative gel of at least 3. (B) Condoms were punctured with either a $26 \mathrm{G}$ or $42 \mathrm{G}$ needle and media was sampled from both the inside (I) and the outside (O) of the condom. The samples were either amplified by PCR directly (left columns) or plated on semi-agar prior to PCR (plaque assay; right columns). M indicates molecular marker and $\mathrm{C}$ indicates a negative (no DNA) PCR control.

\subsection{The effects of acidic pH on the integrity of NRL condoms.}

During sexual intercourse condoms are subjected to acidic conditions ranging from a $\mathrm{pH}$ of 3.8 - $5.0[7,8]$. Effects of this $\mathrm{pH}$ range on the integrity of the condom remained to be adequately tested using a viral challenge. Hence, a range of acidic conditions were first analyzed using a total of 21 condoms from one manufacturer (Manu I; 
Table 1). Three condoms were incubated in each $\mathrm{pH}(3.8,4.0,4.2,4.4,4.6,4.8$, and 5.0) for $1 \mathrm{~h}$ at $26^{\circ} \mathrm{C}$ followed by testing and plaque assay/PCR assessment of viral penetrability using the test conditions optimized above. PCR analysis determined that over 21 condoms there was one fail at pH 4.2 (Fig. 3A). Subsequently, 7 condoms were subjected to a $\mathrm{pH}$ of 4.2 for $1 \mathrm{~h}$ at $26^{\circ} \mathrm{C}$ and results yielded a 1 in 10 failure rate (Fig. 3B). The physical and chemical stresses placed on a condom during sexual intercourse may increase with increased duration of sexual activity. The temporal effects of an acidic environment were tested by incubating a total of 18 condoms from one manufacturer over a time course from $10 \mathrm{~min}$ $-120 \mathrm{~min}$. The results yielded one condom failure at $20 \mathrm{~min}$ post-incubation, indicating no direct correlation to length of time at the lowered $\mathrm{pH}$ (Fig. 2C).

A

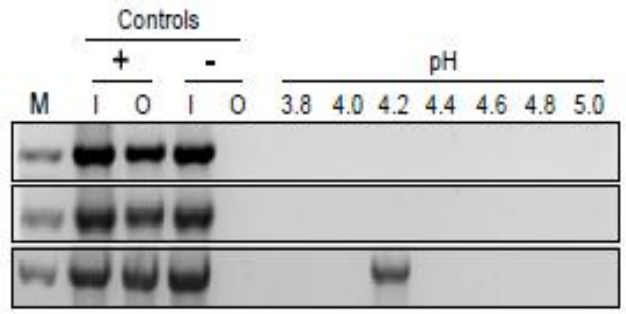

B

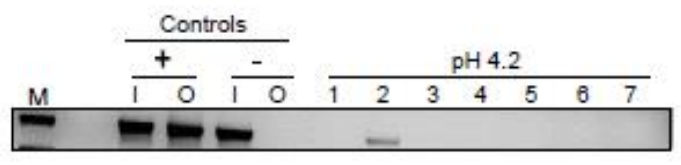

C

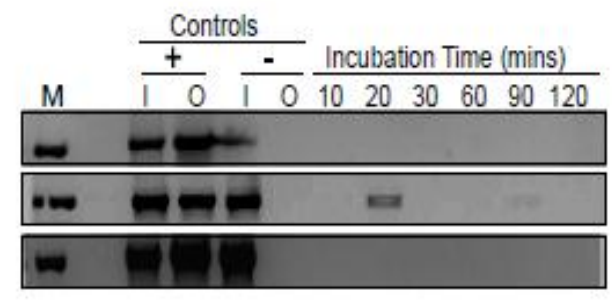

Figure 3. The effects of $\mathrm{pH}$ on condom permeability. One brand of condom was exposed to a number of different $\mathrm{pH}$ conditions as specified below. Positive controls (+) were punctured with a $26 \mathrm{G}$ needle and negative (-) untreated controls were included in each experiment. Water was sampled from inside (I) and outside $(\mathrm{O})$ of the control condoms and just outside $(\mathrm{O})$ of the treated condoms. All samples were plated on semi-agar overnight, followed by PCR amplification of
$2 \mu \mathrm{l}$ of the collected supernatant and agarose gel analysis. $\mathrm{M}$ indicates the molecular marker. (A) 3 condoms were incubated at $26^{\circ} \mathrm{C}$ for $1 \mathrm{~h}$ with each $\mathrm{pH}$ ranging from 3.8-5.0. Media outside the condom was tested at the same time and using the same protocol as the controls. (B) 7 condoms were treated with $\mathrm{pH} 4.2$ for $1 \mathrm{~h}$ at $26^{\circ} \mathrm{C}$ and the media outside of the condom was tested along side of the control condoms. (C) 18 condoms were placed in a container with a water of $\mathrm{pH}$ 4.2. The media outside of 3 condoms were sampled at each time point (10-120 min). Controls were tested directly from the package without incubation in a $\mathrm{pH}$ solution.

\subsection{Testing viral permeability of different brands and styles of condoms.}

The style and morphology of a condom can vary significantly from brand to brand. In addition, many manufacturers alter the latex polymer to introduce flavors, colors or lubricants as well as to etch patterns into the latex; these are proprietary alterations and the effects have not been studied with regard to viral permeability. Hence, to determine whether these modifications altered the susceptibility of the condom to acidic $\mathrm{pH}$ ranges, 9 condoms from 8 different manufacturers with differing characteristics (Table 1) were incubated in solutions of $\mathrm{pH}$ of either $3.8,4.4$, and 5.0 for 1

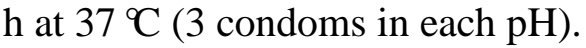

Of the range of $\mathrm{pH}$ conditions both brands $\mathrm{B}$ and $\mathrm{E}$ had a 1:9 failure rate, each at $\mathrm{pH} 5.0$, with the viral titre being significantly higher in brand $\mathrm{B}$. We then re-tested these brands as well as including an additional brand (Brand F) known to be a "thinner" latex condom. We used a $\mathrm{pH}$ of 4.2 and included 10 condoms in each trial. Here again, brands $\mathrm{B}$ and $\mathrm{E}$ each demonstrated a failure and brand $\mathrm{F}$ had 2 failures (Fig. 4B). In total, 48 control condoms were tested with only one failure overall for Brand B (15 of these controls shown). Brands $\mathrm{B}, \mathrm{E}$, and $\mathrm{F}$ showed significantly higher failure rates, $10.5 \%$ for all three, over both $\mathrm{pH}$ treatments as compared to the control condoms which had a failure rate of $2.1 \%$ (Mann-Whitney $\mathrm{p}=0.5$ ). Notably over all of our experiments in 42 cases of control PCR reactions (sample taken from inside the condom) there was $100 \%$ efficiency indicating the consistency of this method (Figs. 24; columns marked I). For 17 positive controls using a $26 \mathrm{G}$ needle there was only 1 negative 
result (Fig. 4B; Brand E), possibly indicative of the thicker latex material for this substance. This indicates that positive controls should be optimized when changing the test material to avoid false negatives.

Table 1. Different brands and styles used in viral penetrability testing

\begin{tabular}{lllll}
\hline Brand & Manu & Thickness $(\mu \mathrm{m})$ & Latex Features & Lubricant Features \\
\hline A & I & 70 & Synthetic dye added to latex & Scents and flavors added \\
B & I & 70 & Plurality of intersecting spirals etched into latex & Basic lubricant \\
C & II & 20 & Monolithic projections on exterior surface & Basic lubricant \\
D & II & 70 & Desensitizing agent on interior surface & Interior lubricant contains \\
B & III & 90 & Benzocaine \\
F & IV & 70 & Thicker latex & Basic lubricant \\
\end{tabular}

*Manufacturer advertises as thinner

A

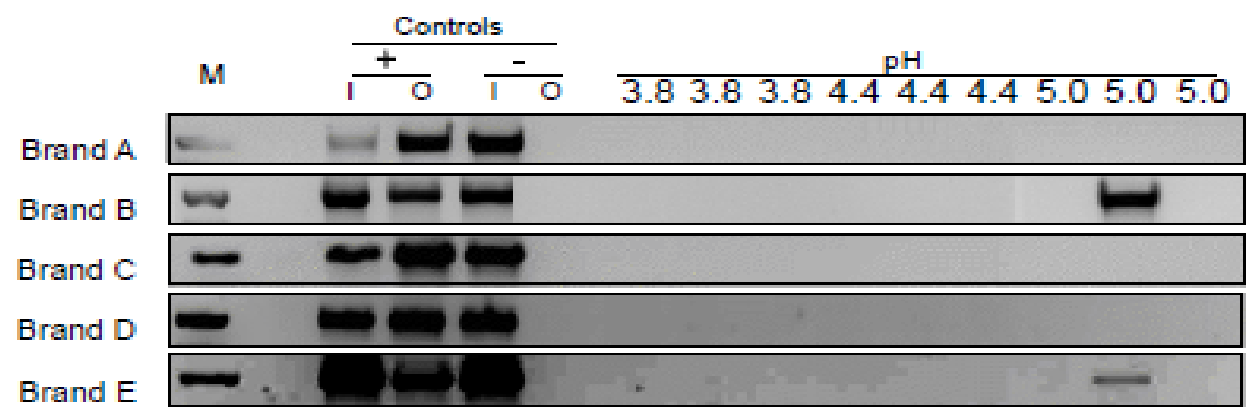

$\mathrm{B}$

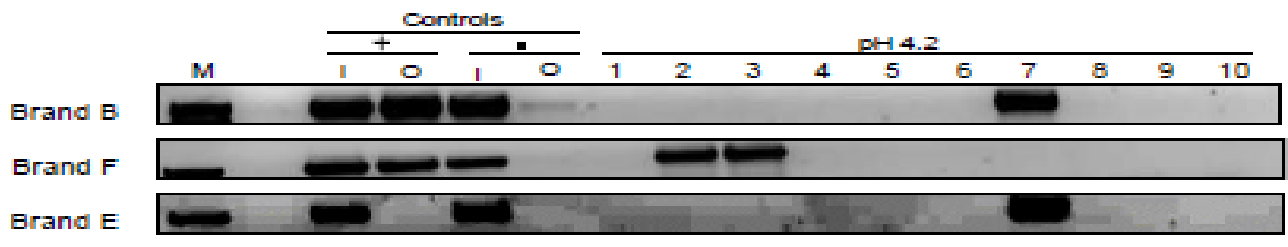

Figure 4. Testing durability of different styles and brands of condoms. A variety of different brands from 4 manufacturers were exposed to acidic pHs for $1 \mathrm{~h}$ at at $26^{\circ} \mathrm{C}$. Positive $(+)$ controls were punctured with a $26 \mathrm{G}$ needle and negative (-) controls were taken directly from the packaging. Water was sampled from inside (I) and outside (O) of the control condoms and just outside (O) of the treated condoms. All samples were plated on semi-agar overnight, followed by PCR amplification and analysis on an agarose gel. M indicates the DNA ladder. (A) For each brand of condom (A-E; left hand axis) 3 condoms were treated with one of each $\mathrm{pH}(3.8,4.4,5.0)$. (B) 10 condoms (indicated by numbers at the top of the columns) of Brands $\mathrm{B}, \mathrm{F}$ and $\mathrm{E}$ were treated with $\mathrm{pH} 4.2$ at and tested for viral penetrability.

\section{Discussion}

Several studies have tested the effectiveness of latex barriers against virus penetration, either using condoms [11] or medical gloves [14]. The
Lytle et al. protocol used DPBS as the incubation media [11] however using water for the incubation media reduces labor and expense of method, an important consideration for expanding the study design. Broyles et al. also demonstrated that using 
water was an acceptable media for this type of experiment [14]. We performed experiments to ensure that we could detect virus incubated in water as opposed to PBS or NB (Fig. 2A). A previous study also determined that amplifying the viral DNA using PCR methods was an efficient mechanism of screening, these results demonstrated a sensitivity of $50 \mathrm{fg}$ [14]. Our studies consistently yielded sensitivities around 18 pg (Fig. 1B). While PCR conditions were identical, the differences in sensitivity between environments may be due to the differences in PCR reagents or purity of the genomic DNA preparation. Importantly, this demonstrates that while an accurate and overall sensitive method there is a considerable range for the detection limit to be expected from this experimental design. Given these results, we further optimized detection by including a plaque assay prior to PCR detection; with this step we were able to detect as

little as $70 \mathrm{PFU} / \mu \mathrm{l}$ of virus and this resulted in $100 \%$ consistency with our positive PCR controls (Figs 1-4). Previous studies reported being unable to consistently detect a PCR product when the sample titre was less than $100 \mathrm{PFU} / \mu \mathrm{l}[14]$, hence including the plaque assay improved reproducibility considerably but also introduced a more laborious and time consuming step which may not be optimal for large scale analysis.

The reported statistical probability of condoms failing varies depending on the type of report in question. Failure rates calculated from women who become pregnant while using NRL condoms as a contraceptive mechanism are estimated to be $2 \%$ when condoms are used in accordance with the manufacturer recommendations [16]. However, when including data from atypical or improper use of condoms, as specified by the manufacturer, the failure rate approaches $15 \%$ [16]. A study determining the viral penetrability of unused latex condoms reported that $2.6 \%$ of condoms allowed virus to penetrate [17]. Our failure rate for control condoms was very close to this value with $2.1 \%$ (1/48 condoms). Using the condoms from Manufacturer I and treating with different $\mathrm{pH}$ treatments yielded a penetrability rate of $4.8 \%$ (Fig. 3A). Focusing on a larger number of condoms treated with a $\mathrm{pH}$ of 4.2 gave a penetrability rate of $20 \%$ (Fig. 3A, B). There were no failures for condoms being exposed to higher $\mathrm{pH}$ values for $2 \mathrm{~h}$ suggesting that the latex was not significantly compromised due to the time period within this sample size (Fig. 3C). The work by Lytle et al. suggested that the holes in the latex closed after a period of time which could also explain why longer times points did show increased penetration by the virus [13]. Neither of the condom styles from manufacturer II allowed virus penetration within this sample size, however increasing the overall sample size is required to definitively make conclusions between various brands of condoms. After treatments with $\mathrm{pH} 4.2$ Brand $\mathrm{B}$ and Brand $\mathrm{E}$ both had 1 failure and Brand $\mathrm{F}$ had 2 failures (Fig. 4A \& B). These results indicate that even within this small sample size the treatment with $\mathrm{pH} 4.2$ significantly affects the integrity of the latex and allows for more virus penetration (Mann-Whitney $\mathrm{p}=0.5$ ). Furthermore, the positive results seen at varying $\mathrm{pHs}$ demonstrate that bacteriophage $\Phi 1 \times 74$ is able to be adequately detected at a wide range of $\mathrm{pHs}$ and hence remains a suitable surrogate in the testing of the integrity of barrier materials. Importantly, understanding the physiological conditions which may affect latex integrity is essential in the prevention of STIs. We have optimized a design that adequately detects failure rates in condoms under a variety of physiologically significant $\mathrm{pHs}$. Our results support that treating different styles and brands of condoms with this acidic $\mathrm{pH}$ range yields failure rates of up to $20 \%$. This work warrants further studies to determine the statistical significance of these findings over a larger sample size.

\section{Conclusion}

This study further optimized a set up for quantifying viral penetration of latex barriers using the surrogate virus bacteriophage $\Phi 174$ and PCR detection. Using these conditions we have determined that a variety of styles and brands of latex condoms are susceptible to failure at physiologically significant $\mathrm{pHs}$ ranging between 4.2-5.0. This study provides impetus to further test the effects of acidic $\mathrm{pH}$ on latex barrier materials 
and may have future implications on the manufacturing and testing of prophylactics.

\section{Abbreviations}

STI, sexually transmitted infection; NRL, natural rubber latex; PCR, polymerase chain reaction; $\Phi$ X174. bacteriophage phiX174; NB, nutrient broth; NA, nutrient agar; PBS, phosphate buffered saline; DNA, deoxyribonucleic acid; OD, optical density; PFU, plaque forming unit.

\section{Acknowledgements}

We gratefully acknowledge Dr. M. Weiss for providing space for this project. We thank the LGBTQ society for providing the Brand B condoms and D. Dorey for technical assistance. This study was funded by an internal University of Windsor grant to Dr. El Masri and Canada Research Chairs Program, Chair in Social Justice and Sexual Health held by Dr. Maticka-Tyndale.

\section{References}

[1] Yeang, H. Y.; Arif, S. A.; Yusof, F.; Sunderasan, E. Allergenic proteins of natural rubber latex, Methods, 2002, 27(1), 32-45 DOI: 10.1016/S1046-2023(02)00049-X

[2] Richards, J. M.; Sydiskis, R. J.; Davidson, W. M.; Josell, S. D.; Lavine, D. S. Permeability of latex gloves after contact with dental materials, Am J Orthod Dentofacial Orthop, 1993, 104(3), 224-229 DOI:10.1016/S08895406(05)81723-8

[3] Connor, T. H.; Laidlaw, J. L.; Theiss, J. C.; Anderson, R. W.; Matney, T. S. Permeability of latex and polyvinyl chloride gloves to carmustine, Am J Hosp Pharm, 1984, 41(4), 676-679

[4] Baumann, M. A.; Rath, B.; Fischer, J. H.; Iffland, R. The permeability of dental procedure and examination gloves by an alcohol based disinfectant, Dent Mater, 2000,
$16(2), 139-144$

DOI:10.1016/S0109-

5641(99)00094-9

[5] Stoikes, M. E.; Carlson, J. D.; Farris, F. F.; Walker, P. R. Permeability of latex and polyvinyl chloride gloves to fluorouracil and methotrexate, Am J Hosp Pharm, 1987, 44(6), 1341-1346

[6] Nakamura, M.; Oshima, H.; Hashimoto, Y. Monomer permeability of disposable dental gloves, J Prosthet Dent, 2003, 90(1), 81-85 DOI: $10.1016 / \mathrm{S} 0022-3913(03) 00178-1$

[7] Linhares, I. M.; Summers, P. R.; Larsen, B.; Giraldo, P. C.; Witkin, S. S. Contemporary perspectives on vaginal $\mathrm{ph}$ and lactobacilli, Am J Obstet Gynecol, 2011, 204(2), 120 e121-125 DOI: 10.1016/j.ajog.2010.07.010

[8] Borges, S. F.; Silva, J. G.; Teixeira, P. C. Survival and biofilm formation of listeria monocytogenes in simulated vaginal fluid: Influence of $\mathrm{ph}$ and strain origin, FEMS Immunol Med Microbiol, 2011, 62(3), 315-320 DOI:10.1111/j.1574695X.2011.00815.x

[9] Maznah, K. S.; Baharin, A.; Hanafi, I.; Azhar, M. E.; Hakim, M. H. M. R. Effect of acid treatment on extractable protein content, crosslink density and tensile properties of natural rubber latex films, Polymer Testing, 2008, 27(7), 823-826 DOI: 10.1016/j.polymertesting.2008.06.004

[10] Herman, B. A.; Carey, R. F.; Rinaldi, J. E. Sensitivity of water leak test for latex condoms, Journal of Testing and Evaluation, 1993, 21(2), 124-128 DOI: 10.1520/JTE11755J

[11] Lytle, C. D.; Routson, L. B.; Cyr, W. H. A simple method to test condoms for penetration by viruses, Appl Environ Microbiol, 1992, 58(9), 3180-3182

[12] Carey, R. F.; Lytle, C. D.; Cyr, W. H. Implications of laboratory tests of condoms integrity, Sexually Transmitted Diseases, 1999, 26(4), 216-220

[13] Lytle, C. D.; Truscott, W.; Budacz, A. P.; Venegas, L.; Routson, L. B.; Cyr, W. H. Important factors for testing barrier materials with surrogate viruses, Appl Environ Microbiol, 1991, 57(9), 2549-2554 
[14] Broyles, M. J.; O'Connell, K. P.; Korniewicz, D. M. PCR-based method for detecting viral penetration of medical exam gloves, Journal of Clinical Microbiology, 2002, 40(8), 2725-2728 DOI: 10.1128/JCM.40.8.27252728.2002

[15] Lytle, C. D.; Routson, L. B. Minimized virus binding for tests of barrier materials, Appl Environ Microbiol, 1995, 61(2), 643-649
[16] Trussell, J. Understanding contraceptive failure, Best Pract Res Clin Obstet Gynaecol, 2009, 23(2), 199-209 DOI: 10.1016/j.bpobgyn.2008.11.008

[17] Lytle, C. D.; Routson, L. B.; Seaborn, G. B.; Dixon, L. G.; Bushar, H. F.; Cyr, W. H. An in vitro evaluation of condoms as barriers to a small virus, Sex Transm Dis, 1997, 24(3), 161-164 